\title{
Association of Initial Twice-Weekly Hemodialysis Treatment with Preservation of Residual Kidney Function in ESRD Patients
}

\author{
Minmin Zhang ${ }^{a}$ Mengjing Wang ${ }^{a}$ Haiming Li ${ }^{a}$ Ping Yu ${ }^{a} \quad$ Li Yuan $^{a}$ \\ Chuanming Hao $^{a}$ Jing Chen ${ }^{a}$ Kamyar Kalantar-Zadeh ${ }^{b}$ \\ a Division of Nephrology, Huashan Hospital, Shanghai Medical College, Fudan University, Shanghai, P.R. China; \\ ${ }^{b}$ Harold Simmons Center for Kidney Disease Research and Epidemiology, Division of Nephrology and Hypertension, \\ University of California Irvine Medical Center, Orange, Calif., USA
}

\section{Key Words}

Hemodialysis frequency · RKF · Adequacy · GFR

\begin{abstract}
Background: Residual kidney function (RKF) has consistently been a predictor of greater survival in maintenance hemodialysis (MHD) patients. The relationship between hemodialysis (HD) treatment frequency and RKF preservation has not been well examined. We hypothesized that initial twiceweekly HD helps in maintaining a longer RKF. Methods: In a dialysis center in Shanghai, 168 ESRD patients were screened and finally 85 patients were identified for this main cohort study. We first examined these 85 MHD patients; 30 of them were initiated with twice-weekly HD for 6 months or longer and 55 patients were started and maintained on thriceweekly HD treatment. Then a subcohort study in 48 incident MHD patients was implemented to assess the independent risk factors responsible for RKF decline during the first year of HD therapy. Multivariate logistic regression analysis was then employed to examine the odds ratio of RKF loss. $\boldsymbol{R e}$ sults: The main cohort study showed that the clinical outcomes were almost the same between the two groups in 85 patients, but the percent of patients with RKF loss was significantly lower in the twice-weekly group compared with the thrice-weekly group, especially during the first year of
\end{abstract}

HD initiation. In the 48 incident MHD patients, we found no significant differences between the two groups except for variations in the HD frequency, weekly Kt/V. The multivariate analysis showed that factors such as the male gender, HD frequency, URR and intradialytic hypotension episode were associated with RKF loss, and the odds ratio of RKF loss for each additional HD treatment per week was 7.2. Conclusion: Twice-weekly HD during the first year of dialysis therapy appears to be associated with better RKF preservation.

(c) 2014 S. Karger AG, Base

\section{Introduction}

The importance of residual kidney function (RKF) has been increasingly recognized as a significant determinant that influences the adequacy and frequency of dialysis, quality of life and mortality in end-stage renal disease (ESRD) patients [1-3]. In addition to providing small solute clearance, RKF continues to maintain important met-

\section{M.Z., M.W. and H.L. contributed equally to this work.}

This work was supported in part by Major State Basic Research Development Program of China (973 program, No. 2012CB517700) and China Natural Science Foundation 81170684 (to Jing Chen).

\section{KARGER}

E-Mail karger@karger.com www.karger.com/ajn
(C) 2014 S. Karger AG, Basel

0250-8095/14/0402-0140\$39.50/0 
abolic, hemodynamic and endocrine functions, and plays a crucial role in maintaining the overall cardiovascular health, nutritional status, mineral metabolism balance and well-being of patients undergoing dialysis [4-6]. Many clinical guidelines have clearly recommended that striving to slow down the RKF loss should be the primary objective of dialysis treatment $[7,8]$.

Even though the importance of the preservation of RKF has been emphasized in the peritoneal dialysis (PD) therapy, less attention has been given to RKF in patients who undergo hemodialysis (HD). Indeed the importance of RFK is often ignored in HD treatment strategies, even though several studies have demonstrated a similar association between RKF loss and mortality or other important clinical outcomes in both PD and HD patients [912]. A more rapid decline in RKF has been noted among patients on $\mathrm{HD}$ compared to those on $\mathrm{PD}$, and most patients nearly completely lose the RKF usually within the first year of dialysis therapy in incident HD patients [1315]. Potential predictors of decline in RKF in HD patients, as mentioned in the literature, are ESRD etiology, level of blood pressure (BP), intradialysis hypotension, extracellular fluid volume depletion, congestive heart failure, use of ultrapure dialysis fluid and biocompatible dialysis membranes; predictors of decline are also mentioned in the literature of various medications [6-18]. A recent study has showed that frequent nocturnal (sixtimes-per-week) HD was associated with faster RKF decline compared to conventional (three-times-per-week) HD [19]. The role of these predictors of RKF loss in HD patients remains to be elucidated in clinical practice. The K-DOQI guidelines state that the required frequency of HD can be achieved by following a three-times-per-week HD regimen in patients with residual native kidney urea clearance of less than $2 \mathrm{ml} / \mathrm{min} / 1.73 \mathrm{~m}^{2}$, but these guidelines do not specify any appropriate recommendations for patients with residual native kidney urea clearance of more than $2 \mathrm{ml} / \mathrm{min} / 1.73 \mathrm{~m}^{2}$ [7].

Low-frequency HD therapy (less than thrice-weekly) is not only widely used in many developing countries and emerging economies including India and China [20-22], but is also used sporadically in Europe and in the United States $[23,24]$. Some studies suggest that compared to the conventional thrice-weekly treatment pattern, no worse and possibly even better survival has been demonstrated in some patients treated with twice-weekly HD including in studies from both the United States Renal Data System (USRDS) and Shanghai Dialysis Registration Database $[20,24]$. Some authors report that patients who had sufficient urine output and who underwent twice-weekly
HD exhibited better preservation of RKF due to fewer intradialytic hypotensive episodes [25]. Incremental dialysis based on the clinical conditions and the rate of RKF decline has been advocated in PD patients for more than a decade [26-28] but very few opinion leaders have paid attention to this concept of HD treatment $[29,30]$.

In the dialysis center of Huashan hospital affiliated to the Fudan University in Shanghai, either thrice-weekly HD or twice-weekly HD is selected for the initial treatment of incident ESRD patients. This decision is made by the attending nephrologist based on the physician's clinical judgment and patient preference, among others, including but not limited to their baseline RKF, comorbid conditions, economic conditions and family situation. Although this kind of decision making is not randomized, there is no uniform guideline for deciding on the treatment regimen and hence the variability is rather large. The current study was designed to compare the rate of RKF decline and other clinical outcomes in incident ESRD patients treated with twice-weekly HD with that of the patients on thrice-weekly HD during the first several months of dialysis initiation, and to confirm whether the initial one-year HD frequency would have any bearing on RKF loss in incident HD patients.

\section{Subjects and Methods}

\section{Participants}

In the first part of the study, we examined a historical cohort by comparing the RKF loss and clinical outcomes in 85 MHD patients with different initial HD frequency in the dialysis center of Huashan hospital (Fudan University, Shanghai, P.R. China). A total of 168 ESRD patients who started MHD therapy after August 2002 and continued the treatment for more than 6 months until the end of September 2012 were screened. They were divided into two groups based on the initial six-month HD frequency: Group A included 58 patients who received twice-weekly HD for at least 6 months and did not switch to the thrice-weekly HD pattern during this period. Group B included 110 MHD patients who started HD treatment thrice-weekly and maintained this regimen so consistently until the end of the cohort. Subsequently, 83 patients were excluded for the following reasons: death $(n=34)$, having severe complications $(n=7)$, being bed-ridden $(n=3)$, experiencing malignancy $(\mathrm{n}=3)$, baseline urine output $<500 \mathrm{ml} /$ day on starting HD treatment $(n=13)$, using non-AVF vascular accesses $(n=6)$, or stopped being part of the study $(n=17)$ because patients either switched over to peritoneal dialysis or got the transplant done, or moved out to another dialysis center. Finally, 85 patients remained in this main cohort study and there was no major bias exhibited during patient selection given the similar demographic and clinical characteristics (table 1). All selected patients were treated with biocompatible membranes (polysulfone), ultrapure water and bicarbonate buffered dialysis fluid throughout the cohort. All the data were collected at the time of enrollment in September 2012. 
Table 1. Details of patient selection in the main cohort study at the time of enrollment

\begin{tabular}{lccl}
\hline & Group A & Group B & p \\
& 2/week HD & 3/week HD & \\
\hline Screen, n & 58 & 110 & \\
Death, \% (n) & $15.52(9)$ & $2.73(25)$ & 0.269 \\
Survival time, year & $10.1 \pm 5.8$ & $6.6 \pm 5.3$ & 0.110 \\
CVD $^{1}$ & $8.62(5)$ & $13.64(15)$ & 0.340 \\
Tumor & $1.72(1)$ & $2.73(3)$ & 1.000 \\
Others & $5.17(3)$ & $6.36(7)$ & 1.000 \\
Transferring, \%(n) & $13.79(8)$ & $8.18(9)$ & 0.252 \\
PD & $1.72(1)$ & $0(0)$ & 0.345 \\
Renal transplantation & $1.72(1)$ & $4.55(5)$ & 0.617 \\
Other HD units & $10.34(6)$ & $3.64(4)$ & 0.015 \\
Exclusion, \% (n) & $18.97(11)$ & $19.09(21)$ & 0.984 \\
Having severe complications & $3.45(2)$ & $4.55(5)$ & 1.000 \\
Being bed-ridden status & $0(0)$ & $22.73(3)$ & 0.512 \\
Experiencing malignancy & $1.72(1)$ & $1.82(2)$ & 1.000 \\
Baseline urine output & & & \\
$\quad<500$ ml/day & $10.34(6)$ & $6.36(7)$ & 0.539 \\
Non-AVF vascular accesses & $3.45(2)$ & $3.64(4)$ & 1.000 \\
Final enrolled, \% (n) & $51.72(30)$ & $50(55)$ & 1.000 \\
\hline
\end{tabular}

${ }^{1}$ Including coronary heart disease or coronary artery disease, cardiac arrhythmia, ischemic cardiomyopathy, heart failure, cardiac sudden death, abnormal angiogram or peripheral vascular disease; ${ }^{2}$ Including advanced liver cirrhosis, active infection, acute myocardial infarction, or other severe diseases. $\mathrm{PD}=$ Peritoneal dialysis; $\mathrm{HD}=$ hemodialysis; $\mathrm{AVF}=$ arteriovenous fistula.

In the second part of the study, we examined a subcohort of 48 incident MHD patients with baseline urine output $>500 \mathrm{ml} /$ day and $\mathrm{HD}$ vintage less than 12 months to find out the independent risk factors associated with the decline of RKF during the first year of HD therapy in the same dialysis center during the same cohort period. This subcohort comprised 32 patients from the main cohort and 16 new patients. The patients were prescribed with twiceor thrice-weekly HD treatment at the start of the study. The exclusion criteria applied were the same as those applied to the main cohort. Demographic and clinical data were obtained 0 to 4 weeks before the start of MHD treatment and at the time of enrollment. RKF loss was defined as a condition when the daily urine output $<200 \mathrm{ml}$

The Ethics Committee on Human Research at Huashan Hospital examined and approved these studies and all patients provided written informed consent.

\section{Data Collection}

Laboratory Parameters

During the enrollment of the patients in our study in September 2012, predialysis blood samples were obtained on the midweek dialysis day for routine laboratory assessment by standard techniques. The baseline estimated GFR of patients in the subcohort study was calculated using the MDRD formula at the initiation of HD therapy [31]. Twenty-four-hour interdialytic urine samples of the day following the hemodialysis treatment session were collected for measuring the RKF, and this urine sample was used to estimate the mean of creatinine and urea clearance [7] of both the main cohort and subcohort studies. The predialysis urea and creatinine were measured on the day before the 24-hour urine samples were collected. The single-pool Kt/V urea delivered by hemodialysis was estimated by the second-generation Daugirdas equation [32]. Adequacy of dialysis in the current study was assessed by weekly Kt/V using spKt/V multiplied by frequency/per week and urea reduction rate (URR) calculated as a percentage of postdialysis blood urea nitrogen (BUN) divided by predialysis BUN. The normalized protein nitrogen appearance (nPNA) was calculated as described by Termorshuizen et al. and normalized to standard body weight (total-body water/0.58) [9]. The total body water was determined using Watson's formula [33].

\section{Clinical Parameters}

Cardiovascular diseases (CVD) such as coronary heart disease or coronary artery disease, cardiac arrhythmia, ischemic cardiomyopathy, heart failure, cardiac sudden death, abnormal angiogram or peripheral vascular disease were present in the cohort. The hospitalization rate was calculated as the total events divided by the total population in the past year from any cause except for AV fistula dysfunction. Intradialytic hypotensive episodes were diagnosed based on the following criteria: a drop of systolic blood pressure greater than $25 \%$ of baseline value or systolic blood pressure lower than $90 \mathrm{~mm} \mathrm{Hg}$ that required rescue fluid supplementation. We also recorded the other factors that could affect the residual GRF, such as congestive heart failure, the other events that lead to dehydration or the decrease of body volume and some medications in use. These comorbid factors were expressed as the total number of episodes happened in a month for each patient.

\section{Statistics Analysis}

The mean \pm SD or number (percentage) was used to summarize the basic characteristics. The differences between the two groups were determined by tests such as Student's t test, chi-square test, and nonparametric statistical test wherever appropriate. Univariate logistic regression was firstly used to analyze the predictors of loss of RKF. Explanatory variables included age, sex, SBP, DBP, $\mathrm{HD}$ frequency, UF rate, weekly Kt/V, URR, intradialytic hypotension episode, BMI, nPNA, usage of ACEI/ARB, CCB, NSAIDS, and phosphate binders. Predictors with $\mathrm{p}<0.20$ were included in the multivariate logistic regression analysis and the algorithm of backward selection was used to determine the significant variables in the best fitted model. Logistic regression analyses were employed to examine the odds ratio (OR) of RKF loss adjusting for confounders. For all comparisons, a p value $<0.05$ was considered statistically significant. All statistical analyses were performed with SAS 9.23 (SPSS, Inc., Chicago, Ill., USA).

\section{Results}

\section{Main Cohort: Less HD Frequency Is Associated with RKF Preservation in MHD Patients}

Thirty patients of Group A started with twice-weekly $\mathrm{HD}$; out of the 30 patients, 6 maintained this treatment 
Table 2. Characteristics of enrolled $85 \mathrm{MHD}$ patients in the main cohort at the time of enrollment

\begin{tabular}{|c|c|c|c|}
\hline & $\begin{array}{l}\text { Group A } \\
\text { 2/week HD } \\
(n=30)\end{array}$ & $\begin{array}{l}\text { Group B } \\
\text { 3/week HD } \\
(\mathrm{n}=55)\end{array}$ & $\mathrm{p}$ \\
\hline \multicolumn{4}{|l|}{ Demographics } \\
\hline Age, years & $59.5 \pm 11.3$ & $63.1 \pm 11.4$ & 0.17 \\
\hline Gender, $\%$ male & 60 & 55 & 0.63 \\
\hline HD vintage, year & $5.6 \pm 3.0$ & $5.9 \pm 3.2$ & 0.64 \\
\hline Initial HD frequency, times/week & $2.00 \pm 0.00$ & $3.00 \pm 0.00$ & $<0.01$ \\
\hline Current HD frequency, times/week & $2.80 \pm 0.41$ & $3.00 \pm 0.00$ & $<0.01$ \\
\hline Ultrafiltration rate, $\mathrm{ml} / \mathrm{session}$ & $2,219 \pm 1,242.73$ & $1,532.8 \pm 1,826.6$ & 0.29 \\
\hline $\mathrm{SpKt} / \mathrm{V}$ & $1.19 \pm 0.24$ & $1.20 \pm 0.18$ & 0.07 \\
\hline Weekly Kt/V & $3.32 \pm 0.66$ & $3.59 \pm 0.53$ & 0.07 \\
\hline URR, \% & $65.1 \pm 6.6$ & $65.7 \pm 11.4$ & 0.83 \\
\hline Systolic BP, mm Hg & $134.0 \pm 19.2$ & $132.9 \pm 25.39$ & 0.84 \\
\hline Diastolic BP, mm Hg & $80.5 \pm 10.7$ & $78.1 \pm 14.3$ & 0.42 \\
\hline \multicolumn{4}{|l|}{ Primary cause of ESRD, \% (n) } \\
\hline Chronic glomerulonephritis & $43(13)$ & $29(16)$ & 0.65 \\
\hline Diabetic nephropathy & $10(3)$ & $18(10)$ & 0.32 \\
\hline Hypertensive nephrosclerosis & $13(4)$ & $20(11)$ & 0.44 \\
\hline Polycystic kidney disease & $3(1)$ & $7(4)$ & 0.65 \\
\hline Other/unknown & $30(9)$ & $26(14)$ & 0.19 \\
\hline \multicolumn{4}{|l|}{ Comorbid conditions } \\
\hline $\mathrm{CVD}^{1}, \%$ & 47 & 53 & 0.79 \\
\hline Hospitalization $^{2}$ & $0.13 \pm 0.35$ & $0.31 \pm 0.90$ & 0.31 \\
\hline \multicolumn{4}{|l|}{ Laboratory values } \\
\hline Hemoglobin, g/dl & $11.3 \pm 1.3$ & $11.1 \pm 1.1$ & 0.43 \\
\hline Albumin, g/dl & $3.97 \pm 0.21$ & $3.94 \pm 0.39$ & 0.69 \\
\hline Total cholesterol, mg/dl & $155 \pm 39$ & $170 \pm 39$ & 0.13 \\
\hline Body mass index & $21.1 \pm 2.9$ & $21.6 \pm 3.5$ & 0.48 \\
\hline nPNA, g/kg per day & $1.10 \pm 0.23$ & $1.11 \pm 0.20$ & 0.89 \\
\hline hsCRP, mg/l & $5.35 \pm 7.87$ & $4.62 \pm 5.63$ & 0.65 \\
\hline Serum phosphorus, mg/dl & $5.3 \pm 1.2$ & $6.0 \pm 1.2$ & 0.04 \\
\hline Serum Calcium, mg/dl & $9.7 \pm 0.9$ & $9.5 \pm 0.8$ & 0.37 \\
\hline iPTH, pg/ml & $228 \pm 147$ & $245 \pm 182$ & 0.70 \\
\hline \multicolumn{4}{|c|}{$\begin{array}{l}\text { Values indicate means } \pm \text { SDs or percentage (number). MHD = Maintenance hemodialysis; } \mathrm{ESRD}=\mathrm{end} \text { stage } \\
\text { renal disease; CVD = cardiovascular disease; } \mathrm{nPNA}=\text { normalized protein nitrogen appearance; hsCRP }=\text { high } \\
\text { sensitive } \mathrm{C} \text { active protein; } \mathrm{PTH}=\text { intact parathyroid hormone. } \\
{ }^{1} \text { Included coronary heart disease or coronary artery disease, cardiac arrhythmia, ischemic cardiomyopathy, } \\
\text { heart failure, cardiac sudden death, abnormal angiogram or peripheral vascular disease. } \\
{ }^{2} \text { Hospitalization rate, calculated as the total events divided by the number of patients in the past year. }\end{array}$} \\
\hline
\end{tabular}

dose until the end of the cohort and $24(80 \%)$ patients switched to thrice-weekly HD after HD treatment for average 1.5 years. They switched over because of reduced urine output, trends of fluid retention, uncontrolled electrolytes imbalance, or patients' preference. Table 2 shows the current data at the time of enrollment in September 2012. The current frequency of HD treatment in Group A (twice-weekly) patients was still lower than that of Group B (thrice-weekly) patients, but weekly Kt/V as well as URR were not significantly different between the two groups, suggesting that twice-weekly treatment can achieve the comparable HD adequacy. The average ultrafiltration rate per HD session was similar between the two groups. There were no significant differences between the two groups in gender, age, HD vintage, blood pressure and primary cause of ESRD. The prevalence of CVD and hospitalization rate in the previous year was also similar in each group of patients. The main biochemical and clin- 
ical measures such as hemoglobin, albumin, total cholesterol, BMI, nPNA, hsCRP, and iPTH showed no difference between the two groups. A slightly lower serum phosphorus was observed in patients of Group A, perhaps due to the higher proportion of patients with adequate RKF in this group (table 3), which might lead to the excretion of phosphorous in the urine.

Table 3 shows that the percentage of patients with RKF (urine volume $\geq 200 \mathrm{ml} /$ day) at the time of enrollment in September 2012 [34] was significantly higher in Group A treated with fewer initial HD frequency compared to Group B treated with regular thrice-weekly HD. The estimated residual GFR in patients with RKF was also greater in Group A than that of Group B, even though the daily urine output did not show any significant changes between the two groups. Accordingly, the percentage of patients with RKF loss (urine volume $<200 \mathrm{ml} /$ day) was significantly lower in Group A compared with Group B. The average time for RFK loss after the start of HD was obviously longer in Group A than in Group B. If subdivided the patients into three $H D$ vintage, the significant difference of RKF loss between Group A and Group B patients was detected only during the first year of $\mathrm{HD}$ treatment. The loss of RKF was more likely to occur within the first year of HD treatment in all patients as shown in figure 1.

\section{Subcohort: HD Frequency Is a Predictor of RKF \\ Decline in MHD Patients}

The main cohort study showed that the percent of patients with RKF loss was significantly lower in the twice-weekly group compared with the thrice-weekly group, especially during the first year; so we further examined 48 patients with MHD vintage less than one year to assess the potential predictors of the decline of RKF. The HD frequency prescribed to these patients was $2.69 \pm 0.43$ times per week. Thirteen patients started and were kept on twice-weekly HD, 10 patients switched to thrice-weekly HD after initiation of twiceweekly HD for an average 3.2 months and the other 25 patients maintained thrice-weekly HD. The percent of the thrice-weekly HD patients in the two groups of the subcohort during the period of the subcohort study is shown in figure 2 . Compared to the 85 patients of the main cohort, the 48 incident patients of the subcohort had better-controlled blood pressure, anemia, mineral metabolism, and nutritional status and less comorbid states (table 4). In the subcohort study, we found no significant differences between the two groups except for the HD frequency, weekly Kt/V as shown in table 4 . The

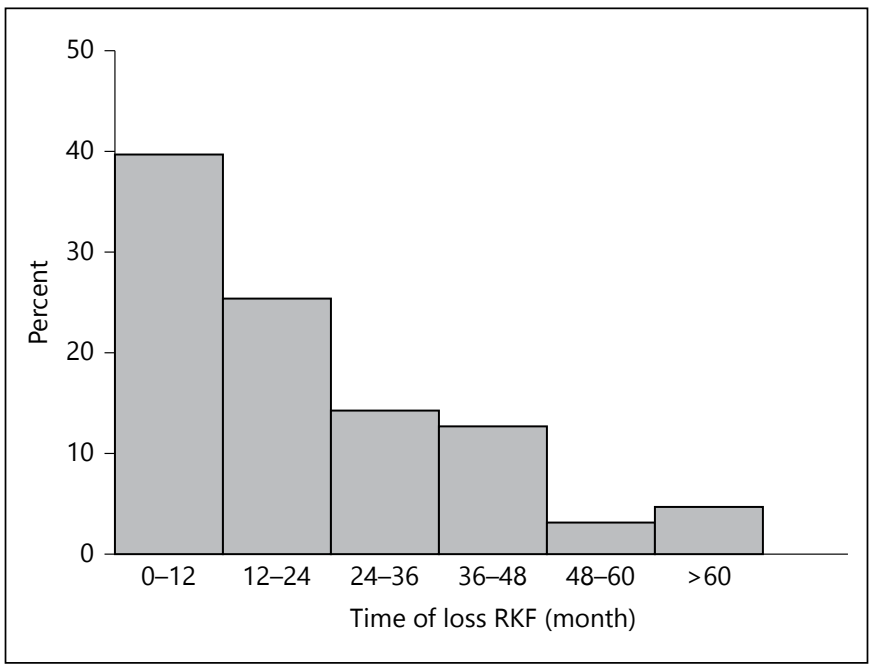

Fig. 1. Time distribution of RKF loss in $85 \mathrm{MHD}$ patients (\%).

Table 3. RKF-related factors of $85 \mathrm{MHD}$ patients currently in the main cohort

\begin{tabular}{|c|c|c|c|}
\hline & $\begin{array}{l}\text { Group A } \\
2 / \text { week HD } \\
(\mathrm{n}=30)\end{array}$ & $\begin{array}{l}\text { Group B } \\
\text { 3/week HD } \\
(n=55)\end{array}$ & $\mathrm{p}$ \\
\hline $\begin{array}{l}\text { Patients with RKF, \% (n) } \\
\text { Residul }\end{array}$ & $40(12)$ & $18(10)$ & 0.03 \\
\hline $\mathrm{ml} / \mathrm{min} / 1.73 \mathrm{~m}^{2}$ & $1.82 \pm 1.97$ & $0.35 \pm 0.29$ & 0.03 \\
\hline Urine output, $\mathrm{ml} /$ day & $579.17 \pm 602.06$ & $390.00 \pm 284.6$ & 0.67 \\
\hline Patients with RKF loss ${ }^{\mathrm{b}}$, & & & \\
\hline$\%(\mathrm{n})$ & $60(18)$ & $82(45)$ & 0.03 \\
\hline$\leq 1$ years on $\mathrm{HD}$ & $10(3)$ & $40(22)$ & 0.02 \\
\hline $1-3$ years on $\mathrm{HD}$ & $37(11)$ & $25(14)$ & 0.28 \\
\hline$>3$ years on $\mathrm{HD}$ & $13(4)$ & $16(9)$ & 0.96 \\
\hline $\begin{array}{l}\text { Average time for RKF loss, } \\
\text { month }\end{array}$ & $33.8 \pm 32.3$ & $20.7 \pm 18.5$ & 0.05 \\
\hline
\end{tabular}

Values indicate means \pm SDs or percentage (number). RKF $=$ Residual kidney function; URR = urea reduction ratio.

${ }^{\text {a }}$ Estimated as the arithmetic mean of creatinine and urea clearance in MHD patients with urine.

${ }^{\mathrm{b}}$ Defined as urine volume $<200 \mathrm{ml} /$ day.

declining percent of the daily urine output was significantly less in the twice-weekly group (46 $\pm 39 \%)$ compared to the thrice-weekly group $(72 \pm 32 \%)(\mathrm{p}=0.02)$. Three patients lost their RKF almost immediately after suffering from acute decompensated heart failure, severe pneumonia with sepsis, and upper gastrointestinal bleeding with substantial blood loss, while the other 45 


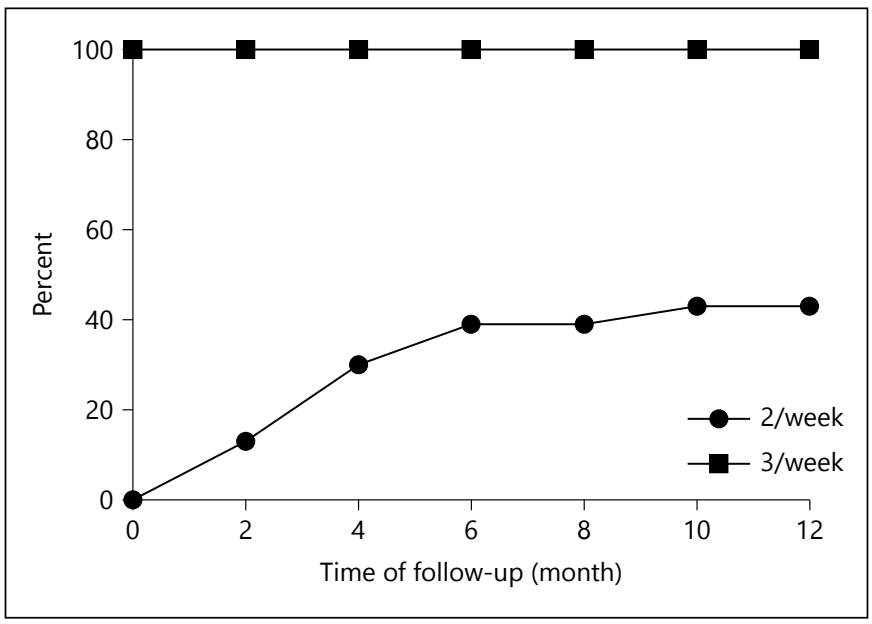

Fig. 2. The percent of the $3 /$ week HD patients in the 2 groups of the subcocort study over the time.

patients exhibited slower decline in their RKF. The previously reported risk factors associated with RKF decline, including intradialytic hypotensive episode, congestive heart failure and other severe conditions leading to dehydration or the decrease of the body volume, are also described in table 4.

The logistic regression analysis of factors associated with RKF loss is reported in table 5. A new variable expressed as the decline rate of GFR, which was adjusted for baseline GFR and dialysis duration, was introduced to further analyze RKF loss in patients. The decline rate of GFR was calculated as: (current GFR - baseline GFR) $\left(\mathrm{ml} / \mathrm{min}\right.$ per $\left.1.73 \mathrm{~m}^{2}\right) /$ dialysis duration (months).

Since data in table 3 suggested that the patients treated with fewer initial HD frequency had less incidence of RKF loss than patients treated with regular thrice-weekly HD, a Receiver Operating Characteristic (ROC) analysis was performed to decide the cut-off value of a $50 \%$ decline rate of GFR in a year for predicting whether the patient has lost RKF or not, as previously reported $[35,36]$. We found the best cut-off value was 0.044 (4.4\%) with a specificity of $75 \%$ and a sensitivity of $64 \%$ (AUC $=0.65, \mathrm{p}<$ 0.05 ) (see online suppl. Appendix; for all online suppl. material, see www.karger.com/doi/10.1159/000365819). Therefore, in following logistic regression analyses, patients with a decline rate of GFR greater than $0.044 \mathrm{ml} /$ min per $1.73 \mathrm{~m}^{2} /$ month were considered having lost the $\mathrm{RKF}$, or else, maintaining the RKF. The univariate variable screening showed that the variables sex, HD frequency, UF rate, URR, and intradialytic hypotension episode were significant at $\mathrm{p}<0.20$ and were considered potential

Table 4. Characteristics of 48 incident MHD patients of the subcohort (dialysis vintage $\leq 12$ months)

$$
\begin{array}{ll}
\begin{array}{l}
\text { 3/week HD } \\
(\mathrm{n}=32)
\end{array} & \begin{array}{l}
2 / \text { week HD } \\
(\mathrm{n}=16)
\end{array}
\end{array}
$$

\section{Demographics}

Age, years

Gender, \% male

Systolic BP, mm Hg

Diastolic BP, $\mathrm{mm} \mathrm{Hg}$

$\begin{array}{ccc}58.1 \pm 11.7 & 59.5 \pm 10.6 & 0.68 \\ 58 & 56 & 0.91 \\ 127.9 \pm 27.5 & 139.5 \pm 20.8 & 0.15 \\ 78.8 \pm 14.2 & 81.6 \pm 12.5 & 0.52\end{array}$

Primary cause of ESRD, \% (n)

Chronic glomerulonephritis

Diabetic nephropathy

Hypertensive nephrosclerosis

Polycystic kidney disease

Other/unknown

\section{$H D$ and $R K F$ related}

$\mathrm{HD}$ vintage, months

HD frequency, times/week

Ultrafiltration rate, $\mathrm{ml} /$ session

Weekly Kt/V

URR, \%

Initial GFR, $\mathrm{ml} / \mathrm{min} / 1.73 \mathrm{~m}^{2}$

Current GFR, $\mathrm{ml} / \mathrm{min} / 1.73 \mathrm{~m}^{2}$

Initial urine output, $\mathrm{ml} /$ day

Current urine output, $\mathrm{ml} /$ day

$19(6)$

$22(7)$

$13(4)$

$19(6)$

$28(9)$

$\begin{array}{ccc}10.8 \pm 2.9 & 9.8 \pm 4.1 & 0.37 \\ 2.97 \pm 0.07 & 2.09 \pm 0.21 & <0.001 \\ 2,186 \pm 869 & 2,378 \pm 1,037 & 0.50 \\ 3.4 \pm 0.6 & 2.6 \pm 0.4 & <0.001 \\ 64.7 \pm 10.1 & 69.4 \pm 6.6 & 0.12 \\ 6.4 \pm 2.4 & 7.2 \pm 2.9 & 0.31 \\ 0.9 \pm 1.0 & 2.4 \pm 2.6 & 0.04 \\ 860 \pm 495 & 1,067 \pm 643 & 0.22 \\ 241 \pm 351 & 558 \pm 559 & 0.05 \\ 47(15) & 25(4) & 0.14\end{array}$

Comorbid factors $^{\mathrm{a}}$

Intradialytic hypotension

Total cholesterol, mg/dl episode $^{\mathrm{b}}$

Congestive heart failure

Others $^{c}$

\section{Laboratory values}

Hemoglobin, g/dl

Albumin, g/dl

Body mass index

nPNA, g/kg/day

hsCRP, mg/l

Serum phosphorus, $\mathrm{mg} / \mathrm{dl}$

Serum Calcium, mg/dl

iPTH, pg/ml

$\begin{array}{lll}0.72 \pm 1.01 & 0.68 \pm 1.19 & 0.92 \\ 0.01 \pm 0.02 & 0.02 \pm 0.03 & 0.28 \\ 0.03 \pm 0.04 & 0.02 \pm 0.03 & 0.17\end{array}$

$\begin{array}{ccc}11.4 \pm 1.5 & 11.3 \pm 1.3 & 0.81 \\ 4.0 \pm 0.3 & 4.0 \pm 0.2 & 0.44 \\ 169.9 \pm 41.7 & 169.9 \pm 50.3 & 0.99 \\ 22.0 \pm 4.0 & 22.7 \pm 3.2 & 0.58 \\ 1.1 \pm 0.3 & 1.2 \pm 0.4 & 0.30 \\ 6.7 \pm 9.6 & 4.1 \pm 5.4 & 0.28 \\ 5.8 \pm 1.3 & 6.1 \pm 1.2 & 0.57 \\ 9.36 \pm 0.76 & 9.05 \pm 1.85 & 0.53 \\ 181.8 \pm 97.4 & 174.3 \pm 113.6 & 0.84\end{array}$

Values indicate mean \pm SDs or percentage (number). MHD = Maintenance hemodialysis; ESRD = end stage renal disease; RKF = residual kidney function; $\mathrm{URR}=$ urea reduction ratio; $\mathrm{nPNA}=$ normalized protein nitrogen appearance; hsCRP $=$ high sensitive $\mathrm{C}$ active protein; $\mathrm{iPTH}=$ intact parathyroid hormone.

a These data indicate the total number of episodes that happened per month in each patient.

${ }^{b}$ Defined as a drop of systolic blood pressure greater than $25 \%$ of basal, or systolic blood pressure lower than $90 \mathrm{~mm} \mathrm{Hg}$ that required rescue fluid supplementation.

${ }^{c}$ Other events leading to dehydration or the decrease of the body volume, such as the shock for any reason, severe infection, gastrointestinal bleeding, etc. These data indicate the total number of episodes that happened per month in each patient. 
Table 5. Odds ratios for the likelihood of RKF loss in 48 incident MHD patients based on logistic regression analyses

\begin{tabular}{|c|c|c|c|c|c|c|}
\hline \multirow[t]{2}{*}{ Factor } & \multicolumn{3}{|c|}{ Univariate } & \multicolumn{3}{|c|}{ Multivariate } \\
\hline & OR & $95 \% \mathrm{CI}$ & $\mathrm{p}$ & OR & $95 \% \mathrm{CI}$ & $\mathrm{p}$ \\
\hline Age, years & 0.96 & $0.91-1.02$ & 0.96 & - & & \\
\hline Sex, male to female & 0.34 & $0.10-1.16$ & 0.09 & 0.08 & $0.01-0.64$ & 0.02 \\
\hline $\mathrm{SBP}, \mathrm{mm} \mathrm{Hg}$ & 1.00 & $0.98-1.02$ & 0.87 & - & & \\
\hline $\mathrm{DBP}, \mathrm{mm} \mathrm{Hg}$ & 1.00 & $0.96-1.05$ & 0.88 & - & & \\
\hline HD frequency, time/week & 3.38 & $0.83-13.75$ & 0.09 & 7.20 & $1.10-47.09$ & 0.04 \\
\hline UF rate, $\mathrm{ml}$ & 1.00 & $1.00-1.00$ & 0.20 & - & & \\
\hline Weekly, Kt/V & 1.59 & $0.63-4.01$ & 0.33 & - & & \\
\hline URR, \% & 0.94 & $0.87-1.02$ & 0.15 & 0.85 & $0.72-0.998$ & 0.05 \\
\hline \multicolumn{7}{|l|}{ Intradialytic hypotension } \\
\hline episode, each episode & 2.04 & $0.92-4.54$ & 0.08 & 2.51 & $1.06-5.95$ & 0.04 \\
\hline $\mathrm{BMI}, \mathrm{kg} / \mathrm{m}^{2}$ & 1.02 & $0.88-1.20$ & 0.77 & - & & \\
\hline nPNA, g/kg/day & 0.37 & $0.05-2.64$ & 0.32 & - & & \\
\hline ACEI/ARB, yes vs. no & 1.42 & $0.43-4.63$ & 0.56 & - & & \\
\hline CCB, yes vs. no & 1.13 & $0.33-3.86$ & 0.85 & - & & \\
\hline NSAIDS, yes vs. no & 0.38 & $0.03-4.51$ & 0.44 & - & & \\
\hline Phosphate binders, yes vs. no & 2.82 & $0.46-17.21$ & 0.26 & - & & \\
\hline
\end{tabular}

$\mathrm{RKF}=$ Residual kidney function; $\mathrm{URR}=$ urea reduction ratio; $\mathrm{ACE}=$ angiotensin-converting enzyme; $\mathrm{ARB}=$ angiotensin receptor blocker; NSAIDS = nonsteroidal anti-inflammatory drugs.

predictors of RKF loss in the multivariate analysis. The multivariate analysis found that the male gender (OR, 0.08 ; 95\% CI, 0.01-0.64; $\mathrm{p}=0.018)$, HD frequency (OR, 7.2; 95\% CI, 1.10-47.09; $\mathrm{p}=0.039)$, URR (OR, 0.85; 95\% CI, 0.72-0.998; $\mathrm{p}=0.047$ ), and intradialytic hypotension episode (OR, 2.51; 95\% CI, 1.06-5.95; $\mathrm{p}=0.036$ ) were statistically significant with RKF loss. An increase of one HD per week or 1 episode of intradialytic hypotension during the initial first year treatment increased the risk of RKF loss about 7.20- and 2.51-fold in MHD patients and incident MHD patients respectively. An increase of $1 \%$ in URR was associated with a relatively $15 \%$ risk reduction of RKF loss.

\section{Discussion}

In this historical cohort study of $85 \mathrm{MHD}$ patients in Shanghai, we found that patients who underwent twiceweekly HD for 6 months or longer had better RKF than patients who started and maintained thrice-weekly HD treatment; there was no significant difference between the two groups in terms of HD adequacy, biochemical measures, cardiovascular comorbidity or hospitalization rates. The rate of RKF loss (defined as urine volume $<200$ $\mathrm{ml}$ /day) was significantly lower in the twice-weekly group compared with the thrice-weekly group, especially during the first year of HD initiation ( 10 vs. $40 \%, p=0.03$ ). In a subcohort of 48 incident MHD patients who received on average $2.69 \pm 0.43 \mathrm{HD}$ treatments per week, the odds ratio of RKF loss for each additional HD treatment per week was 7.2 (95\% confidence interval: 1.1-47.1, $\mathrm{p}=0.04$ ). These unprecedented data have major clinical implications as they suggest that twice-weekly HD during the first year of dialysis therapy is associated with substantially better RKF preservation.

Preservation of RKF is considered an important goal in the management of patients with ESRD, irrespective of the choice of dialysis modality, be it HD or PD therapy [1, $2,37]$. However, evidence regarding the factors influencing the decline rate of RKF in HD patients is not clear. The present data suggest that the HD frequency (twice vs. thrice weekly) during the first 6 months of dialysis initiation was associated with the decline of RKF in MHD patients, which we believe has led to a clinically relevant discovery in that RKF could be preserved by modulating the HD frequency during the first year of dialysis initiation.

Even though thrice-per-week HD is recommended as the standard of care to achieve adequate HD dose to 
ESRD patients by K-DOQI guidelines, twice-weekly $\mathrm{HD}$ is widely used as the initial treatment in China, India and many other developing countries for a variety of clinical and economic reasons [20,21]. Lin et al. demonstrated that ESRD patients with sufficient RKF may safely undergo twice-weekly HD without suffering from inadequate dialysis dose and may maintain better RKF than patients on thrice-weekly HD, although this difference was not systematically analyzed as we did here [25]. Data from Shanghai Dialysis Registry showed that patients with twice-weekly HD had similar or even higher survival rates compared to the thrice-weekly HD patients [20]. A large study by Hanson et al. indicated that the overall mortality risk for patients treated with twice-weekly HD was $24 \%$ lower than those on thriceweekly $\mathrm{HD}$, which might be due to the higher pre-existing RKF [24]. Fernandez-Lucas et al. also suggested that initially, HD can be administered on a progressively increasing dosage, and to begin with two sessions per week was a safe prescription to preserve RKF [29]. However, this is still not the final conclusion. A recent study indicated a different result that patients dialyzed less than three times per week survived shorter than patients receiving a higher dialysis dose and frequency [38]. Therefore, the exact effects of dialysis frequency on survival outcomes of MHD patients should be further explored through prospective clinical trials. Although the present study was performed in the surviving MHD patients, the data clearly revealed that twice-weekly HD during the first several months after dialysis initiation did not produce any adverse effects; it also did not compromise the dialysis adequacy or long-term clinical outcomes of MHD patients but resulted in beneficial effects on slowing the loss of RKF compared to patients who followed the thrice-weekly HD pattern. In our study, all patients had sufficient RKF before the start of HD but the outcome was significantly different. Even though it may seem that patients in better clinical conditions, such as with more residual GFR, less fluid retention and manageable comorbid conditions, are assigned to twiceweekly $\mathrm{HD}$ as the initial treatment, in many cases, the selection of HD frequency also relates to patient choice, the level of compliance and the economic conditions. In our dialysis center, if the patient's general health shows no deteriorating trends during the first several months of twice-weekly, the patient maintains twice-weekly HD treatment; however, if there are concerns or deteriorating trends, then the twice-weekly patient is convinced to switch over to the thrice-weekly treatment, and this usually occurs in the first year of MHD initia-

Twice-Weekly Hemodialysis and Preservation of RKF tion. This practice can partly explain as to why the two groups of patients in our study, despite different initial HD frequency, showed no significant difference in their blood pressure, cardiovascular complications, hospitalization rates, nutritional status and comorbid conditions after five years of MHD treatment, even though the thrice-weekly HD group received 50\% more HD treatment during the initial several months than the twice-weekly counterpart. A biologically plausible reason for our observed favorable outcomes in the twiceweekly group is the better preservation of RKF in these patients, which may offset the potential disadvantage of low frequent $\mathrm{HD}$ such as treatment inadequacy and guarantee survival and the clinical outcome $[20,23,24$, 39].

The relationship between the frequency of HD treatment and RKF preservation has aroused many interests recently. In Frequent Hemodialysis Network Daily and Nocturnal Trials, Daugirdas et al. reported that participants randomized to six-times-per-week nocturnal HD showed a more rapid decline in RKF compared with participants on conventional thrice-weekly HD. However, whether RKF also declined with frequent daily treatment was not determined [19]. Another study from Taiwan indicated that patients dialyzed twice-weekly had a slower decline of RKF, fewer intra-dialytic hypotensive episodes, and fewer hospitalizations versus those on thrice-weekly HD [25]. The present study further indicated that HD frequency during the initial several months is an independent predictor of RKF loss in MHD patients and an increase of one HD per week during the first one year might increase the risk of RKF loss 7.20-fold in incident patients. One plausible reason for this may be related to the lower incidence of ischaemia and the lower intradialytic hypotensive episodes, leading to less frequent and milder ischemic damage to the remnant kidneys and, hence, leading to less frequent both of acute kidney injury, which per se is a cause of worsening CKD [40]. Since in our study both HD frequency and intradialytic hypotension were independent predictors of RKF loss in the multivariate analyses, it is reasonable to speculate that the lower HD frequency may play a role using additional mechanisms, such as $30 \%$ less exposure to HD therapy and its inherent complications and less exposure to nephrotoxic drugs or agents that are given with each HD treatment [41]. It is well known that the HD process may induce chronic inflammatory response and oxidative damage in MHD patients because of biocompatibility, no matter how biocompatible the dialysis membranes are declared to be [42-44]. A higher HD frequency will cause more 
exposure of this blood-to-circuit contact activation process, leading to persistent damage in the remnant kidneys and accelerate the loss of RKF [19, 40, 42] Furthermore, Bricker's 'intact nephron hypothesis' [45] provides an additional assumption that the remaining nephrons could be preserved better when there is more accumulated uremic substances, which might be the stimulus for the remaining (intact) nephrons to function as super nephrons. Therefore, selecting less frequent, such as twice-weekly HD treatment as an initial treatment to ESRD patients with sufficient RKF may contribute to better RKF preservation and long-term clinical outcomes.

In accordance with the previous studies $[16,17,46]$, the present data confirmed that the total number of intradialytic hypotension episodes is an independent risk factor for the rapid decline of RKF in MHD patients. Overzealous ECF volume depletion resulting in subclinical hypovolemia and reduced blood perfusion in remnant nephrons may aggravate the damage and promote the loss of RKF in ESRD patients $[47,48]$. Both intradialytic hypotension in HD patients and clinically evident dehydration in $\mathrm{PD}$ patients are considered to be among the most important determinants for RKF loss [17, 49]. Although the patients on twice-weekly HD might require a greater UF per HD session due to longer interdialytic intervals than thrice-weekly HD patients, no difference in UF rate was observed between the two groups of patients in either the main cohort study or subcohort study. Moreover, we did not find any significant correlation between the UF rate and intradialytic hypotension or RKF loss in the incident MHD patients. Similar results were also reported in other studies [20].

The association between dialysis adequacy and RKF preservation is not quite clear. Theoretically, adequate dialysis can effectively remove uremic toxins, improve fluid balance and homeostasis, which may contribute to the better preservation of RKF $[9,26]$. In our study, the higher URR has been found to reduce the risk of RKF decline, although the weekly $\mathrm{Kt} / \mathrm{V}$ did not show significant correlation with RKF loss. There seems to be some possibility of bias in the assessment of weekly Kt/V in this study. Since the formula of $\mathrm{spKt} / \mathrm{V}$ is derived from patients treated with thrice-weekly HD [32], this metrics may have inherent limitation for application on twice-weekly HD patients. Some literature has showed that URR is closely associated with the mortality of HD patients and the patients' survival rate could improve with the improvement of URR [50]. It can be speculated that the clearance of urea during HD treatment may be more sensitive to predict the decline of RKF in patients treated with different frequency of HD. Another interesting finding in the current study is that the female gender was a predictor of increased risk of RKF loss in MHD patients, which is in contrast to the previous report [16]. However, the reason for this finding is not clear.

Considerable evidence suggests that certain medications, such as ACE inhibitors [51-53], calcium channel blockers (CCB) $[54,55]$ and NSAIDs $[4,56]$ may affect RKF loss among maintenance patients undergoing dialysis. In a prospective study by $\mathrm{Li}$ et al., $46 \mathrm{PD}$ patients treated with ramipril showed a slower rate of RKF loss compared with the control group [51]. Moist et al. also demonstrated that the effect of ACEI and CCB, which was adjusted for mean arterial pressure (MAP), was significant in the total and PD-only analyses but was not significant in the HD population [16]. Thus, blockade of the renin-angiotensin system is considered to be a standard therapy to preserve RKF in PD patients currently $[5,51]$, although much less is known about the protective effects of ACEI/ARB or other medications in HD patients. The findings from our study suggest that none of the medications such as ACEI/ARB, CCB, NSAIDs or phosphorus binders would predict the progression of RKF loss in incident HD patients. With the emerging importance of RKF in HD patients, the pending question of whether these have a true effect on RKF loss remains relevant and deserves further research.

Our study does have several limitations. First, we enrolled only a small number of participants and followed a limited time course, in particular, because we had decided to study only those patients undergoing dialysis who had significant residual kidney function $(\geq 500 \mathrm{ml} /$ day) at baseline and who had an AV fistula and who survived the first 6 months of the dialysis therapy. The latter selection criteria were implemented since dialysis mortality is extremely high during the first 6 months of dialysis therapy [57]. Second, this was a retrospective cohort study, in which HD frequency was not assigned randomly and the results may be biased, although our inclusion and exclusion criteria led to 2 more commensurate groups at baseline. Third, the impact on mortality was not monitored in this study since only surviving patients were enrolled. Multicenter prospective randomized control trials are needed to circumvent these limitations.

In conclusion, present data demonstrated that twiceweekly HD for the first 6 months or longer upon dialysis initiation helped protect RKF and did not bring about worse clinical outcomes or HD inadequacy in ESRD patients with sufficient RKF. The higher (thrice-weekly) ini- 
tial HD frequency during the first year treatment may indeed be an independent risk factor to promote faster decline in residual GFR in incident ESRD patients. In clinical practice, it is worth exploring the optimal initial $\mathrm{HD}$ frequency in patients with RKF. Initiation of HD with twice-weekly schedules and gradual transition to thriceweekly therapy as RKF declines leading to the more convenient and likely better lifestyle status in ESRD patients may save lives and can improve outcomes. Conducting additional studies on this subject is an urgent need of the hour.

\section{Acknowledgments}

We are grateful to all patients and medical staff who participated in this project. This work was supported in part by Major State Basic Research Development Program of China (973 program, No.2012CB517700) and China Natural Science Foundation 81170684 (to Jing Chen).

\section{Disclosure Statement}

No.

\section{References}

1 Perl J, Bargman JM: The importance of residual kidney function for patients on dialysis: a critical review. Am J Kidney Dis 2009;53: 1068-1081.

- Vilar E, Farrington K: Emerging importance of residual renal function in end-stage renal failure. Semin Dial 2011;24:487-494.

-3 Shafi T, Jaar BG, Plantinga LC, Fink NE, Sadler JH, Parekh RS, Powe NR, Coresh J: Association of residual urine output with mortality, quality of life, and inflammation in incident hemodialysis patients: the Choices for Healthy Outcomes in Caring for End-Stage Renal Disease (CHOICE) Study. Am J Kidney Dis 2010;56:348-358.

4 Brener ZZ, Kotanko P, Thijssen S, Winchester JF, Bergman M: Clinical benefit of preserving residual renal function in dialysis patients: an update for clinicians. Am J Med Sci 2010;339: 453-456.

5 Wang AY, Lai KN: The importance of residual renal function in dialysis patients. Kidney Int 2006;69:1726-1732.

6 Thomas J, Teitelbaum I: Preservation of residual renal function in dialysis patients. Adv Perit Dial 2011;27:112-117.

7 Hemodialysis Adequacy 2006 Work Group: Clinical practice guidelines for hemodialysis adequacy, update 2006. Am J Kidney Dis 2006;48(suppl 1):S2-S90.

-8 Lo WK, Bargman JM, Burkart J, Krediet RT, Pollock C, Kawanishi H, Blake PG; ISPD Adequacy of Peritoneal Dialysis Working Group: Guideline on targets for solute and fluid removal in adult patients on chronic peritoneal dialysis. Perit Dial Int 2006;26:520-522.

-9 Termorshuizen F, Dekker FW, van Manen JG, Korevaar JC, Boeschoten EW, Krediet RT; NECOSAD Study Group: Relative contribution of residual renal function and different measures of adequacy to survival in hemodialysis patients: an analysis of the Netherlands Cooperative Study on the Adequacy of Dialysis (NECOSAD)-2. J Am Soc Nephrol 2004; 15:1061-1070.

10 van der Wal WM, Noordzij M, Dekker FW, Boeschoten EW, Krediet RT, Korevaar JC,
Geskus RB; Netherlands Cooperative Study on the Adequacy of Dialysis Study Group (NECOSAD): Full loss of residual renal function causes higher mortality in dialysis patients; findings from a marginal structural model. Nephrol Dial Transplant 2011;26: 2978-2983.

11 Liao CT, Chen YM, Shiao CC, Hu FC, Huang JW, Kao TW, Chuang HF, Hung KY, Wu KD, Tsai TJ: Rate of decline of residual renal function is associated with all-cause mortality and technique failure in patients on long-term peritoneal dialysis. Nephrol Dial Transplant 2009;24:2909-2914.

12 Wang AY, Wang M, Woo J, Lam CW, Lui SF, Li PK, Sanderson JE: Inflammation, residual kidney function, and cardiac hypertrophy are interrelated and combine adversely to enhance mortality and cardiovascular death risk of peritoneal dialysis patients. J Am Soc Nephrol 2004;15:2186-2194.

13 Tam P: Peritoneal dialysis and preservation of residual renal function. Perit Dial Int 2009; 29(suppl 2):S108-S110.

14 Misra M, Vonesh E, Van Stone JC, Moore HL, Prowant B, Nolph KD: Effect of cause and time of dropout on the residual GFR: a comparative analysis of the decline of GFR on dialysis. Kidney Int 2001;59:754-763.

15 Marron B, Remon C, Perez-Fontan M, Quiros $\mathrm{P}$, Ortiz A: Benefits of preserving residual renal function in peritoneal dialysis. Kidney Int Suppl 2008;suppl:S42-S51.

16 Moist LM, Port FK, Orzol SM, Young EW, Ostbye T, Wolfe RA, Hulbert-Shearon T, Jones CA, Bloembergen WE: Predictors of loss of residual renal function among new dialysis patients. J Am Soc Nephrol 2000;11:556-564.

17 Jansen MA, Hart AA, Korevaar JC, Dekker FW, Boeschoten EW, Krediet RT; NECOSAD Study Group: Predictors of the rate of decline of residual renal function in incident dialysis patients. Kidney Int 2002;62:1046-1053.

-18 Schiffl H, Lang SM, Fischer R: Ultrapure dialysis fluid slows loss of residual renal function in new dialysis patients. Nephrol Dial Transplant 2002;17:1814-1818.
19 Daugirdas JT, Greene T, Rocco MV, Kaysen GA, Depner TA, Levin NW, Chertow GM, Ornt DB, Raimann JG, Larive B, Kliger AS; FHN Trial Group: Effect of frequent hemodialysis on residual kidney function. Kidney Int 2013;83:949-958.

20 Lin X, Yan Y, Ni Z, Gu L, Zhu M, Dai H, Zhang W, Qian J: Clinical outcome of twiceweekly hemodialysis patients in shanghai. Blood Purif 2012;33:66-72.

21 Elamin S, Abu-Aisha H: Reaching target hemoglobin level and having a functioning arteriovenous fistula significantly improve one year survival in twice weekly hemodialysis. Arab J Nephrol Transplant 2012;5:81-86.

22 Bieber B, Qian J, Anand S, Yan Y, Chen N, Wang M, Wang M, Zuo L, Hou FF, Pisoni RL, Robinson BM, Ramirez SP: Two-times weekly hemodialysis in China: frequency, associated patient and treatment characteristics and quality of life in the China dialysis outcomes and practice patterns study. Nephrol Dial Transplant 2013;0:1-10 [Epub ahead of print].

23 Couchoud C, Kooman J, Finne P, Leivestad T, Stojceva-Taneva O, Ponikvar JB, Collart F, Kramar R, de Francisco A, Jager KJ; QUality European STudies Working Group on Dialysis Adequacy: From registry data collection to international comparisons: examples of haemodialysis duration and frequency. Nephrol Dial Transplant 2009;24:217-224.

-24 Hanson JA, Hulbert-Shearon TE, Ojo AO, Port FK, Wolfe RA, Agodoa LY, Daugirdas JT: Prescription of twice-weekly hemodialysis in the USA. Am J Nephrol 1999;19:625-633.

25 Lin YF, Huang JW, Wu MS, Chu TS, Lin SL, Chen YM, Tsai TJ, Wu KD: Comparison of residual renal function in patients undergoing twice-weekly versus three-times-weekly haemodialysis. Nephrology (Carlton) 2009; 14:59-64

26 Viglino G, Neri L, Barbieri S: Incremental peritoneal dialysis: effects on the choice of dialysis modality, residual renal function and adequacy. Kidney Int Suppl 2008;suppl:S52S55. 
27 McCormick BB, Mujais S, Poirier F, Page N, 38 Stankuviene A, Ziginskiene E, Kuzminskis V, Lavoie S: Metabolic effects of incremental doses of intraperitoneal amino acids on automated peritoneal dialysis. Perit Dial Int 2010; 30:201-207.

28 Golper TA: Incremental dialysis. J Am Soc Nephrol 1998;9:S107-S111.

29 Fernandez-Lucas M, Teruel-Briones JL, Gomis-Couto A, Villacorta-Perez J, QueredaRodriguez-Navarro C: Maintaining residual renal function in patients on haemodialysis: 5 -year experience using a progressively increasing dialysis regimen. Nefrologia 2012;32: 767-776.

30 Rhee CM, Unruh M, Chen J, Kovesdy CP, Zager P, Kalantar-Zadeh K: Infrequent dialysis: a new paradigm for hemodialysis initiation. Semin Dial 2013;26:720-727.

-31 Levey AS, Bosch JP, Lewis JB, Greene T, Rogers N, Roth D: A more accurate method to estimate glomerular filtration rate from serum creatinine: a new prediction equation. Modification of Diet in Renal Disease Study Group. Ann Intern Med 1999;130:461-470.

32 Daugirdas JT: Second generation logarithmic estimates of single-pool variable volume $\mathrm{Kt} / \mathrm{V}$ : an analysis of error. J Am Soc Nephrol 1993;4:1205-1213.

33 Watson PE, Watson ID, Batt RD: Total body water volumes for adult males and females estimated from simple anthropometric measurements. Am J Clin Nutr 1980;33:27-39.

-34 Wang M, You L, Li H, Lin Y, Zhang Z, Hao C, Chen J: Association of circulating fibroblast growth factor-23 with renal phosphate excretion among hemodialysis patients with residual renal function. Clin J Am Soc Nephrol 2013;8:116-125.

-35 Tian SL, Tian XK, Han QF, Axelsson J, Wang T: Presence of peripheral arterial disease predicts loss of residual renal function in incident CAPD patients. Perit Dial Int 2012;32:67-72.

- 36 Kang SH, Cho KH, Park JW, Yoon KW, Do JY: Proteinuria as a risk factor for decline in residual renal function in non-diabetic peritoneal dialysis patients. Kidney Blood Press Res 2013;37:199-210.

37 Krediet RT: How to preserve residual renal function in patients with chronic kidney disease and on dialysis? Nephrol Dial Transplant 2006;21(suppl 2):S42-S46.
Bumblyte IA: Impact of hemodialysis dose and frequency on survival of patients on chronic hemodialysis in Lithuania during 1998-2005. Medicina (Kaunas) 2010;46:516521.

39 Vilar E, Wellsted D, Chandna SM, Greenwood RN, Farrington K: Residual renal function improves outcome in incremental haemodialysis despite reduced dialysis dose. Nephrol Dial Transplant 2009;24:2502-2510.

40 Manns M, Sigler MH, Teehan BP: Intradialytic renal haemodynamics - potential consequences for the management of the patient with acute renal failure. Nephrol Dial Transplant 1997;12:870-872.

41 Pastan S, Bailey J: Dialysis therapy. N Engl J Med 1998;338:1428-1437.

42 Daugirdas JT, Bernardo AA: Hemodialysis effect on platelet count and function and hemodialysis-associated thrombocytopenia. Kidney Int 2012;82:147-157.

43 Pertosa G, Grandaliano G, Gesualdo L, Schena FP: Clinical relevance of cytokine production in hemodialysis. Kidney Int Suppl 2000; 76:S104-S111.

44 Kalousova M, Sulkova S, Fialova L, Soukupová J, Malbohan IM, Spacek P, Braun M, Mikulíková L, Fortová M, Horejsí M, Tesar V, Zima T: Glycoxidation and inflammation in chronic haemodialysis patients. Nephrol Dial Transplant 2003;18:2577-2581.

45 Bricker NS, Morrin PA, Kime SW Jr: The pathologic physiology of chronic Bright's disease: an exposition of the 'intact nephron hypothesis'. J Am Soc Nephrol 1997;8:14701476.

46 Shoji T, Tsubakihara Y, Fujii M, Imai E: Hemodialysis-associated hypotension as an independent risk factor for two-year mortality in hemodialysis patients. Kidney Int 2004;66: 1212-1220.

47 Kinet JP, Soyeur D, Balland N, Saint-Remy M Collignon P, Godon JP: Hemodynamic study of hypotension during hemodialysis. Kidney Int 1982;21:868-876.

48 Cavalcanti S, Ciandrini A, Severi S, Badiali F, Bini S, Gattiani A, Cagnoli L, Santoro A: Model-based study of the effects of the hemodialysis technique on the compensatory response to hypovolemia. Kidney Int 2004;65:14991510.
49 Liao CT, Shiao CC, Huang JW, Hung KY, Chuang HF, Chen YM, Wu KD, Tsai TJ: Predictors of faster decline of residual renal function in Taiwanese peritoneal dialysis patients. Perit Dial Int 2008;28(suppl 3):S191-S195.

50 Chertow GM, Owen WF, Lazarus JM, Lew NL, Lowrie EG: Exploring the reverse Jshaped curve between urea reduction ratio and mortality. Kidney Int 1999;56:18721878.

51 Li PK, Chow KM, Wong TY, Leung CB, Szeto CC: Effects of an angiotensin-converting enzyme inhibitor on residual renal function in patients receiving peritoneal dialysis: a randomized, controlled study. Ann Intern Med 2003;139:105-112.

52 Lewis EJ, Hunsicker LG, Bain RP, Rohde RD: The effect of angiotensin-converting-enzyme inhibition on diabetic nephropathy. The Collaborative Study Group. N Engl J Med 1993; 329:1456-1462.

53 Maschio G, Alberti D, Janin G, Locatelli F, Mann JF, Motolese M, Ponticelli C, Ritz E, Zucchelli P: Effect of the angiotensin-converting-enzyme inhibitor benazepril on the progression of chronic renal insufficiency. The Angiotensin-Converting-Enzyme Inhibition in Progressive Renal Insufficiency Study Group. N Engl J Med 1996;334:939_ 945

54 Dworkin LD, Benstein JA, Parker M, Tolbert E, Feiner HD: Calcium antagonists and converting enzyme inhibitors reduce renal injury by different mechanisms. Kidney Int 1993;43: 808-814.

55 Bakris GL: Renal effects of calcium antagonists in diabetes mellitus: an overview of studies in animal models and in humans. Am J Hypertens 1991;4:487S-493S.

56 Musu M, Finco G, Antonucci R, Polati E, Sanna D, Evangelista M, Ribuffo D, Schweiger V, Fanos V: Acute nephrotoxicity of NSAID from the foetus to the adult. Eur Rev Med Pharmacol Sci 2011;15:1461-1472.

57 Lukowsky LR, Kheifets L, Arah OA, Nissenson AR, Kalantar-Zadeh K: Patterns and predictors of early mortality in incident hemodialysis patients: new insights. Am J Nephrol 2012;35:548-558. 